\title{
Angiotensin converting enzyme gene polymorphism in Korean patients with primary knee osteoarthritis
}

\author{
Seung-Jae Hong ${ }^{1}$, Hyung-In Yang ${ }^{1}$, \\ Myung Chul Yoo ${ }^{2}$, Chang-Sik $\mathrm{In}^{3}$, \\ Sung-Vin Yim ${ }^{4}$, Sheng-Yu Jin ${ }^{5}$, \\ Bong-Keun $\mathrm{Choe}^{5}$ and Joo-Ho Chung ${ }^{5,6}$ \\ 'Division of Rheumatology, Department of Internal Medicine \\ College of Medicine \\ 2Department of Orthopedic Surgery, College of Medicine \\ ${ }^{3}$ Department of Acupuncture, College of Oriental Medicine \\ Kyung Hee University, Seoul 130-702, Korea \\ ${ }^{4}$ Department of Pharmacology, College of Medicine \\ Kangwon National University, Hyosa-dong \\ Chunchon, Kangwon-do 200-701, Korea \\ ${ }^{5}$ Kohwang Medical Research Institute, College of Medicine \\ Kyung Hee University, Seoul 130-701, Korea \\ ${ }^{6}$ Corresponding author: Tel, 82-2-961-0281; \\ Fax, 82-2-968-0560; E-mail, hsj718@hanmir.com
}

Accepted 20 May 2003

Abbreviations: ACE, angiotensin converting enzyme; $O A$, osteoarthritis; PCR, polymerase chain reaction; RFLP, restriction fragment length polymorphism

\begin{abstract}
Angiotensin converting enzyme (ACE) plays an important role in the physiology of vasculature, blood pressure and inflammation. ACE gene, known to have insertion/deletion (V/D) polymorphism, has been widely investigated in its relation with cardiovascular and neurodegenerative diseases and longevity. ACE gene polymorphism in an inflammation associated osteoarthritis (OA) patients is not known. Here we have investigated ACE gene polymorphism in 142 Korean primary knee OA patients and 135 healthy volunteers to establish any clinical correlates between ACE polymorphism and knee osteoarthritis. Clinical parameters such as disease onset age, Kellgren-Lawrence grade and Lequesne's functional index provided additional analysis of the relationship of ACE polymorphism and clinical features of $O A$. Early onset $O A$ showed significantly higher allele frequency and carriage rate of $I$ than late onset $O A$. Radiographically severe and functionally poor $O A$ showed higher carriage rate of $\mathrm{I}$ allele than radiogra-
\end{abstract}

phically mild and functionally good $O A$, respectively. This study first reports ACE gene polymorphism to be a risk factor for early onset, severe form primary knee $O A$.

Keywords: angiotensin converting enzyme; osteoarthritis; polymorphism; risk factor

\section{Introduction}

Angiotensin converting enzyme (ACE) is responsible for the conversion of angiotensin I to angiotensin II, which is a potent vasoconstrictor of the renin-angiotensin system, and it also inactivates bradykinin, a vasodilator of the kallikrein-kinin system (Viitanen et al., 2001), which has major implication in inflammatory process including osteoarthritis (Cassim et al., 2002). ACE gene insertion/deletion (I/D) polymorphism is localized in intron 16 of the human ACE gene and it corresponds to an alu repetitive sequence about 287 bp long (Asamoah et al., 1996).

Osteoarthritis (OA) is the most common musculoskeletal disorder world-wide, and a multifactorial disorder in which aging, genetic, hormonal and mechanical factors are all major contributors to its onset and progression (Ghosh et al., 2001). OA disorder suggested to be influenced by multiple genes as genetic risk factors in the form common population polymorphisms (Reginato et al., 2002). Such genetic contribution for the development of OA was once estimated to be as high as 65\% (MacGregor et al., 1999; Shin et al., 2001). In the patients with internal derangements and osteoarthritis of the temporomandibular joints, bradykinin and the score of synovitis shows positive correlation and higher detection rate of bradykinin among several pain-related mediators (Nishimura et al., 2002). ACE is upregulated in synovial stroma in rheumatoid arthritis, thereby contributing to synovial hypoxia and proliferation (Walsh et al., 2000; Min et al., 2001) Therefore, ACE appears to show a great potential to influence the process of vascular control and joint inflammation.

In the present study, we explored the distribution of ACE genotype experimentally and the severity of knee $O A$ clinically to investigate the correlation of ACE polymorphism with knee OA disease severity. This study suggests ACE gene polymorphism as a prognostic factor of OA. 


\section{Material and Methods}

\section{Study population}

This study included 135 healthy control subjects and 160 patients with primary knee OA at the rheumatology clinic, Kyung Hee University Medical Center in Seoul, Korea. Inclusion criteria were primary OA with any symptom and/or sign of $O A$, positive finding in radiographs according to Kellgren-Lawrence grading, informed consent, and no evidence of arthritis due to other disease. This project has been reviewed and approved by the ethics review committee, the Medical Research Institute, Kyung Hee University Medical Center.

Healthy control subjects were chosen from adult volunteers cleared yearly health examinations. Primary knee $O A$ patients were sequentially included in this study from March 1, 2002 to October 31, 2002 with rheumatologist's diagnosis and informed consent of patients. Total 135 control subjects and 142 patients constituted study population.

\section{Clinical informations and classification of $O A$}

Patient's history taking, physical examination and radiographic finding provided clinical informations of patients. In addition, demographic characteristics (age and sex), height, weight and date of onset, clinical features on disease severity were observed by way of Kellgren-Lawrence grade (Kellgren et al., 1957) and Lequesne's functional index (Lequesne et al., 1987). Kellgren-Lawrence grade represents disease severity reflected on radiographs and Lequesne's functional index represents functional or symptomatic status of patients.

The mean disease onset age of 52 years provided the classification of the early onset $O A$ as the $O A$ started before 52 year old and the late onset $O A$ as the OA started above 52 years old. Radiographic findings of OA were classified into mild (KellgrenLawrence grade 1 or 2) or severe (Kellgren-Lawrence grade 3 or 4 ). Functional or symptomatic status of patients was classified into good (Lequesne's functional index $\mathrm{I} \leq 10$ ) or poor (Lequesne's functional index $>10$ ).

\section{Genotype determination}

Peripheral blood samples for DNA extraction from all subjects were collected in EDTA tube. Genomic DNA was extracted from the white blood cells with the use of DNA isolation kit for mammalian blood (MACHEREYNAGEL GmbH \& Co., Dren, Germany). The ACE gene $I$ and $D$ alleles were identified on the basis of polymerase chain reaction (PCR) amplification of the respective fragments from intron 16 of the gene, as previously described (Asamoah et al., 1996). The

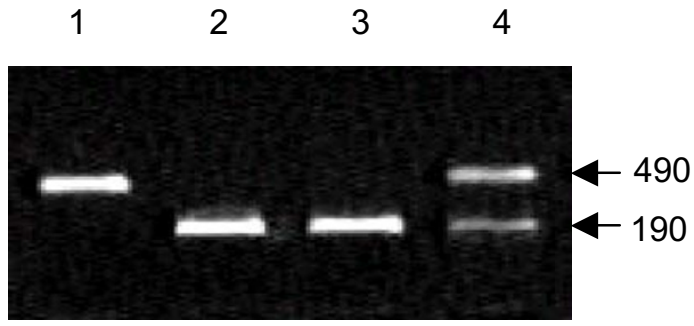

Figure 1. Electrophoresis of the PCR products of the ACE gene. Lane 1 is insertion homozygotes $(I / /)$. Lane 2 and 3 are deletion homozygotes (D/D). Lane 4 is insertion/deletion type heterozygotes (I/D).

sense oligonucleotide primer used was 5'-CTG GAG ACC ACT CCC ATC CTT TCT-3', and the antisense primer was 5'-GAT GTG GCC ATC ACA TTC GTC AGA T-3' as previously published. $100 \mathrm{ng}$ of template DNA was mixed with 10 pmole sense primer $0.5 \mu \mathrm{l}$, 10 pmole antisense primer $0.5 \mu \mathrm{l}, 2.5 \mathrm{mM}$ dNTP 0.7 $\mu$, Taq polymerase $0.3 \mu$ (BioTools, Canada), in a final volume of $40 \mu \mathrm{l}$, and amplified through denaturation at $95^{\circ} \mathrm{C}$ for 2 min followed by 35 cycles of denaturation at $94^{\circ} \mathrm{C}$ for $30 \mathrm{~s}$, annealing at $60^{\circ} \mathrm{C}$ for $30 \mathrm{~s}$ and extension at $72^{\circ} \mathrm{C}$ for $1 \mathrm{~min}$, followed by final extension at $72^{\circ} \mathrm{C}$ for 5 min using Perkin Elmer GeneAmp PCR system 9600 (Roche Diagnostic Systems; Seo et al., 2002). PCR products were analyzed with $2 \%$ agarose gel electrophoresis and ethidium bromide staining with one of following three patterns identified (Figure 1): a $490 \mathrm{bp}$ fragment I (with insertion, genotype II), a $190 \mathrm{bp}$ fragment D (without insertion, genotype DD) or both 490 and 190 bp fragments (with and without insertion, genotype ID).

\section{Statistical analysis}

The clinical data of subgroups with OA patients were compared using the unpaired t-test. The distribution of the ACE I/D genotypes for patients and control subjects were compared using the chi-square test. The odds ratios (OR) and 95\% confidence intervals $(\mathrm{Cl})$ were calculated to quantify the association with early onset, severe form OA. All tests were 2-tailed, at the $5 \%$ level of significance. The SAS statistical package (release 6.12, SAS Institute Inc) was used.

\section{Results}

\section{Subject characteristics}

142 OA patients entered this study, 94 women, 48 men, mean $\pm S D$ age $58.6 \pm 9.4$ years (range $34-86$ ), while 135 healthy control subjects consisted of 91 women and 44 men, mean $\pm S D$ age $59.9 \pm 8.5$ years (range 40-75) with no significant differences between 
Table 1. Clinical characteristics of the 142 Korean primary knee osteoarthritis patients.

\begin{tabular}{ll}
\hline & $\begin{array}{c}\text { All patients } \\
(n=142)\end{array}$ \\
\hline Average age (year, mean $\pm \mathrm{SD})$ & $58.6 \pm 9.4$ \\
No. of female/male & $94 / 48$ \\
Body mass index (kg/m ${ }^{2}$, mean $\left.\pm \mathrm{SD}\right)$ & $25.2 \pm 3.0$ \\
Onset age (year, mean $\pm \mathrm{SD})$ & $52.0 \pm 9.3$ \\
Duration of OA (year, mean $\pm \mathrm{SD})$ & $6.6 \pm 6.7$ \\
Kellgren-Lawrence grade (No.) & \\
1 & 6 \\
2 & 79 \\
3 & 53 \\
4 & 4 \\
Lequesne's indices (mean $\pm \mathrm{SD})$ & $10.1 \pm 2.4$ \\
\hline
\end{tabular}

Table 2. Polymorphic distributions and allelic frequencies of ACE gene in osteoarthritis patients and Korean control subjects.

\begin{tabular}{cccc}
\hline ACE gene & $\begin{array}{c}\text { Patients } \\
n=142(\%)\end{array}$ & $\begin{array}{c}\text { Controls } \\
n=135(\%)\end{array}$ & $P$ value \\
\hline $\begin{array}{c}\text { Genotype } \\
\text { II }\end{array}$ & $51(35.9)$ & $44(32.6)$ & NS \\
ID & $68(47.9)$ & $58(43.0)$ & \\
DD & $23(16.2)$ & $33(24.4)$ & \\
Allele & & & \\
I & 59.9 & 54.1 & NS \\
D & 40.1 & 45.9 & \\
Carrier & & & NS \\
I & 83.8 & 75.6 & \\
D & 64.1 & 67.4 & \\
\hline
\end{tabular}

NS, non-significant.

Table 3. Analysis of clinical subgroups by disease onset age.

\begin{tabular}{|c|c|c|c|c|c|c|}
\hline & $\begin{array}{c}\text { Early onset* } \\
n=83(\%)\end{array}$ & $\begin{array}{l}\text { Late onset } \\
n=59(\%)\end{array}$ & OR $(95 \% \mathrm{Cl})$ & $P$ value ${ }^{a}$ & OR $(95 \% \mathrm{Cl})$ & $P$ value ${ }^{\mathrm{b}}$ \\
\hline \multicolumn{7}{|l|}{ Clinical subgroup } \\
\hline $\mathrm{K}-\mathrm{L}$ grade & $2.3 \pm 0.6$ & $2.5 \pm 0.7$ & & & & \\
\hline Functional index & $10.1 \pm 2.5$ & $10.0 \pm 2.3$ & & & & \\
\hline \multicolumn{7}{|l|}{ Genotype } \\
\hline ॥ & $33(39.8)$ & $18(30.5)$ & & NS & & NS \\
\hline ID & $43(51.8)$ & $25(42.4)$ & & NS & & NS \\
\hline DD & $7(8.4)$ & $16(27.1)$ & $0.2(0.1-0.6)$ & 0.0029 & $0.3(0.1-0.7)$ & 0.0030 \\
\hline \multicolumn{7}{|l|}{ Allele } \\
\hline I & 66.2 & 51.9 & $1.8(1.0-2.9)$ & 0.0180 & $1.6(1.1-2.4)$ & 0.0171 \\
\hline $\mathrm{D}$ & 33.8 & 48.1 & & & & \\
\hline \multicolumn{7}{|l|}{ Carrier } \\
\hline I & 91.6 & 72.9 & $4.3(1.8-9.9)$ & 0.0004 & $3.6(1.5-8.5)$ & 0.0020 \\
\hline $\mathrm{D}$ & 60.2 & 69.5 & & NS & & NS \\
\hline
\end{tabular}

*The mean age at onset in the osteoarthritis $(\mathrm{OA})$ patients was 52.0 year, so early onset is $\leq 52$ year and late onset is $>52$ year. Unpaired t-test of clinical subgroups was performed to compare early onset patients and late onset patients. But, statistical significance was not found. ${ }^{2}$ The $\chi^{2}$ test was performed to compare the genotype distribution, allele frequency and carriage rate of ACE gene in early onset OA patients with that in late onset OA patients. The $P$ value was calculated at 2 degrees of freedom. ${ }^{b}$ The $\chi^{2}$ test was performed to compare the ACE gene in early onset OA patients with that in normal controls. K-L grade, Kellgren-Lawrence grade; OR, odds ratio; $\mathrm{Cl}$, confidence interval; NS, non-significant.

two groups. Characteristics of patients such as body mass index, Kellgren-Lawrence grade, duration of $O A$, Lequesne's index are summarized in Table 1.

\section{Distribution of ACE genotype in controls and patients}

Distribution of genotype, allele frequencies and car- riage rate in the control subjects and patients are shown in Table 2. For the ACE I/D polymorphism there was no significant difference in either the genotype distribution, the allele frequencies and carriage rate between control subjects and patients. 
Table 4. Analysis of clinical subgroups by Kellgren-Lawrence grade.

\begin{tabular}{|c|c|c|c|c|c|c|}
\hline & $\begin{array}{c}\text { Severe }^{*}(\mathrm{Gr} .3,4) \\
n=57(\%)\end{array}$ & $\begin{array}{c}\text { Mild (Gr.1,2) } \\
n=85(\%)\end{array}$ & OR $(95 \% \mathrm{Cl})$ & $P$ value $^{a}$ & OR $(95 \% \mathrm{Cl})$ & $P$ value $^{\mathrm{b}}$ \\
\hline \multicolumn{7}{|l|}{ Clinical subgroup } \\
\hline Onset age & $53.7 \pm 9.1$ & $51.0 \pm 9.4$ & & & & \\
\hline Functional index & $10.9 \pm 2.4$ & $9.4 \pm 2.2$ & & & & \\
\hline \multicolumn{7}{|l|}{ Genotype } \\
\hline ॥ & $21(36.8)$ & $30(35.3)$ & & NS & & NS \\
\hline ID & $31(54.4)$ & $37(43.5)$ & & NS & & NS \\
\hline DD & $5(8.8)$ & $18(21.2)$ & $0.4(0.1-1.0)$ & 0.0492 & $0.3(0.1-0.8)$ & 0.0128 \\
\hline \multicolumn{7}{|l|}{ Allele } \\
\hline I & 63.9 & 57.2 & & NS & & NS \\
\hline $\mathrm{D}$ & 36.1 & 42.8 & & & & \\
\hline \multicolumn{7}{|l|}{ Carrier } \\
\hline 1 & 91.2 & 78.8 & $2.7(1.2-6.2)$ & 0.0175 & $3.2(1.4-7.3)$ & 0.0043 \\
\hline $\mathrm{D}$ & 63.2 & 64.7 & & NS & & NS \\
\hline
\end{tabular}

*Grade 3 and 4 are severe progression, and Grade 1 and 2 are mild progression patients Kellgren-Lawrence grade. Unpaired t-test of clinical subgroups was performed to compare early onset patients and late onset patients. But, statistical significance was not found. ${ }^{2}$ The $\chi^{2}$ test was performed to compare the genotype distribution, allele frequency and carriage rate of ACE gene in severe OA patients with that in mild $\mathrm{OA}$ patients. The $P$ value was calculated at 2 degrees of freedom. ${ }^{\text {b }}$ The $\chi^{2}$ test was performed to compare the ACE gene in severe OA patients with that in normal controls. OR, odds ratio; $\mathrm{Cl}$, confidence interval; NS, non-significant.

\section{Effect of ACE polymorphism on the risk of early onset $O A$}

Early onset $O A$ patients are defined as those whose onset age $\leq 52$ years, while late onset $O A$ onset age $>52$ years. The subgroups, clinical genotype, allele frequencies and carriage rates in the early onset $O A$ group and late onset OA group are shown in Table 3. The frequency of II, ID, DD genotypes of ACE polymorphism were $33(39.8 \%), 43(51.8 \%), 7(8.4 \%)$ in the early onset OA. The frequency of non-DD subtypes such as II and ID was significantly higher than that in late onset $O A$ patients $(P=0.0029$, OR $=0.2)$ or in normal controls $(P=0.0030, \mathrm{OR}=0.3)$.

Allelic frequencies and carriage rates showed significant difference between early onset and late onset groups $(P=0.0180, P=0.0004$ respectively), with the odd ratios of I allele 1.8 and 4.3 respectively. Allelic frequencies and carriage rates showed significant difference between early onset and normal control groups $(P=0.0171, P=0.0020$ respectively), with the odd ratios of $I$ allele 1.6 and 3.6 respectively. Therefore, early onset $O A$ patients showed higher allele frequency and carriage rate of I allele.

\section{Effect of ACE polymorphism on the risk of radiographically severe $O A$}

Radiographically severe OA patients are defined as those whose Kellgren-Lawrence grade 3 or 4 , while radiographically mild $O A$ Kellgren-Lawrence grade 1 or 2. The genotype, allele frequencies and carriage rates between two groups are shown in Table 4. The frequency of II, ID, DD genotypes was $21(36.8 \%)$, $31(54.4 \%), 5(8.8 \%)$ in the radiographically severe $\mathrm{OA}$. The frequency of non-DD subtypes such as II and ID was significantly higher than that in mild $O A$ patients $(P=0.0492, \mathrm{OR}=0.4)$ or in normal controls $(P=0.0128, \mathrm{OR}=0.3)$. Allelic frequencies showed no significant difference between severe $O A$ and mild $O A$ groups $(P>0.05)$, and between severe $O A$ and normal control groups $(P>0.05)$ respectively. Carriage rates of I allele showed significant difference between severe $O A$ and mild $O A$ groups $(P=0.0175$, $O R=2.7$ ), and between severe $O A$ and normal control groups $(P=0.0043, \mathrm{OR}=3.2)$ respectively. Therefore, radiographically severe OA patients showed higher carriage rate of $I$ allele.

\section{Effect of ACE polymorphism on the risk of functionally poor $O A$}

Functionally or symptomatically poor OA patients are defined as those whose Lequesne's functional index $>10$, while functionally or symptomatically good $\mathrm{OA}$ patients are Lequesne's functional index $\leq 10$. The genotype, allele frequencies and carriage rates in the functionally poor $O A$ patients group and functionally good OA patients group are shown in Table 5. The frequency of II, ID, DD genotypes was $21(36.2 \%)$, 
Table 5. Analysis of clinical subgroups by Lequesne's functional index.

\begin{tabular}{|c|c|c|c|c|c|c|}
\hline & $\begin{array}{l}\text { Poor index } \\
n=58(\%)\end{array}$ & $\begin{array}{l}\text { Good index } \\
n=84(\%)\end{array}$ & OR $(95 \% \mathrm{Cl})$ & $P$ value $^{a}$ & OR $(95 \% \mathrm{Cl})$ & $P$ value $^{\mathrm{b}}$ \\
\hline \multicolumn{7}{|l|}{ Clinical subgroup } \\
\hline Onset age & $53.1 \pm 10.5$ & $51.2 \pm 8.5$ & & & & \\
\hline NK-L grade & $2.5 \pm 0.7$ & $2.3 \pm 0.5$ & & & & \\
\hline \multicolumn{7}{|l|}{ Genotype } \\
\hline ॥ & $21(36.2)$ & $30(35.7)$ & & NS & & NS \\
\hline ID & $33(56.9)$ & $35(41.7)$ & & NS & & NS \\
\hline DD & $4(6.9)$ & $19(22.6)$ & $0.3(0.1-0.8)$ & 0.0124 & $0.2(0.1-0.7)$ & 0.0086 \\
\hline \multicolumn{7}{|l|}{ Allele } \\
\hline I & 64.7 & 56.5 & & NS & & NS \\
\hline $\mathrm{D}$ & 35.3 & 43.5 & & & & \\
\hline \multicolumn{7}{|l|}{ Carrier } \\
\hline I & 93.1 & 77.4 & $4.0(1.6-9.7)$ & 0.0015 & $4.2(1.7-10.3)$ & 0.0009 \\
\hline $\mathrm{D}$ & 63.8 & 64.3 & & NS & & NS \\
\hline
\end{tabular}

*Index score $>10$ is poor and score $\leq 10$ is poor patients by Lequesne's functional index. Unpaired t-test of clinical subgroups was performed to compare early onset patients and late onset patients. But, statistical significance was not found. ${ }^{2}$ The $\chi^{2}$ test was performed to compare the genotype distribution, allele frequency and carriage rate of ACE gene in poor OA patients with that in fair OA patients. The $P$ value was calculated at 2 degrees of freedom. ${ }^{b}$ The $\chi^{2}$ test was performed to compare the genotype distribution of ACE gene in poor OA patients with that in normal controls. K-L grade, Kellgren-Lawrence grade; $\mathrm{OR}$, odds ratio; $\mathrm{Cl}$, confidence interval; NS, non-significant.

$33(56.9 \%), 4(6.9 \%)$ in the functionally poor OA. The frequency of non-DD subtypes such as II and ID was significantly higher than that in functionally good $O A$ patients $(P=0.0124, \mathrm{OR}=0.3)$ or in normal controls $(P=0.0086, \mathrm{OR}=0.2)$. Allelic frequencies showed no significant differences between poor $O A$ and good $O A$ groups $(P>0.05)$, and between severe $O A$ and normal control groups, respectively $(P>0.05)$. Carriage rates of I allele showed significant difference between poor $\mathrm{OA}$ and good $\mathrm{OA}$ groups $(P=0.0015, \mathrm{OR}=4.0)$, and between poor $O A$ and normal control groups $(P$ $=0.0009, \mathrm{OR}=4.2$ ) respectively.

\section{Discussion}

Primary $O A$ is a common and multifactorial disease with major genetic component (s) and difficult to analyze due to its high frequency in the general population and extensive clinical heterogeneity (Loughlin et al., 2002). Until now, there has not been any such study for a possible association between ACE gene polymorphism and primary $O A$, especially knee patients. In this study, we have examined any correlates between with the clinical severity of knee $O A$ and ACE polymorphisms in a genetically homogeneous Korean population. The distributions of the $D$ and I alleles and the DD, ID and II genotypes in control subjects were different from that in Caucasian po- pulation. Generally, ethnic origin should be carefully considered while studying the association between genetic factors and disease susceptibility due to the presence of significant discrepancies of genetic polymorphism among populations of different genetic background. Allele frequencies of the ACE gene polymorphism have been reported to vary among racial and ethnic groups. For example, the frequency of the $D$ allele in normal Caucasians is $50-58 \%$, but $35-39 \%$ in normal Chinese (Jeng et al., 1997; Sharma et al., 1998; Lin et al., 2002). In our study, the frequency of $\mathrm{I}>\mathrm{D}$ allele and the distributions rate of ID $>$ II $>$ DD in the control subjects are similar to the previously reported distributions for Japanese (Ishigami et al., 1995), Chinese (Lee et al., 1994) and Koreans (Park et al., 1997). Therefore, it is possible that an association study of the ACE gene and primary OA between Korean and Caucasian might have different results.

In humans, the levels of both plasma ACE and peripheral cellular ACE are genetically determined (Cambien et al., 1988; Rigat et al., 1990), but there are some who report no associated with genetic factor (McKenzie et al., 1995). A deletion (D) polymorphism in the ACE gene has been found to be significantly associated with increased risk of myocardial infarction in some Caucasians (Cambien et al., 1992), essential hypertension in African Americans (Asamoah et al., 1996), higher left ventricular mass index 
and thicker wall (Gharavi et al., 1996), coronary heart disease, myocardial infarction and both diabetic and non-diabetic renal disease (Kennon et al., 1999). On the other hand, I allele has been associated with the risk for Alzheimer's disease and the increase of human longevity (Schachter et al., 1994; Kehoe et al., 1999). However, the association between I/D polymorphism and disease susceptibility is controversial in the Parkinson's disease (Lin et al., 2002) and autoimmune manifestations in sarcoidosis (Papadopoulos et al., 2000).

In this study, there was no significant difference in the distribution of genotype or allelic frequency between control subjects and patients with primary $O A$. These results suggest that the ACE polymorphism is not involved in primary knee OA. In addition, analysis for the association of OA patient by clinical parameters and genotype distribution showed a positive association of I carriage (non-DD genotype) with early onset, functionally poor and radiographically severe primary knee OA. The allele frequency of I was significantly higher in early onset $O A$. This finding suggests that I allele has been associated with the risk for severity of primary $O A$ disease, especially early onset OA. In OA patients, plasma and tissue kallikreins levels were elevated in synovial fluid, kinin levels raised and kinin B2 receptors in synovial lining cells up-regulated (Cassim et al., 1997). Kinins have been implicated in the pathogenesis of experimental and clinical inflammatory arthritis. Therefore, we could speculate that the I allele of ACE gene polymorphism may be a link between the clinical features of $O A$ and ACE activity, especially effects on kallikrein-kininogen system of ACE.

In conclusion, this finding of ACE gene polymorphism associated with the severe form primary knee OA patients could serve as a plausible risk factor of early onset. Further study on a larger population remains to be conducted for a definitive affirmation of correlates of ACE polymorphism on the arthritis.

\section{Acknowledgment}

This study was supported by a Biomedical Brain Research Center grant from the Ministry of Health and Welfare of the Republic of Korea (01-PJ8-PG601NE01-0003).

\section{References}

Asamoah A, Yanamandra K, Thurmon TF, Richter R, Green $R$, Lakin $T$, Martin C. A deletion in the angiotensin converting enzyme (ACE) gene is common among African Americans with essential hypertension. Clin Chim Acta 1996;254:41-6

Cambien F, Alhenc-Gelas F, Herbeth B, Andre JL, Rako- tovao R, Gonzales, MF, Allegrini J, Bloch C. Familial resemblance of plasma angiotensin-converting enzyme level: The Nancy study. Am J Hum Genet 1988;43:774-80

Cambien F, Poirier O, Lecerf L, Evans A, Cambou JP, Arveiler D, Luc G, Bard JM, Bara L, Ricard S, Tiret L, Amouyel $P$, Alhenc-Gelas $P$, Souvrief $F$. Deletion polymorphism in the gene for angiotensin-converting enzyme is a potent risk factor for myocardial infarction. Nature 1992;359:641-4

Cassim B, Naidoo S, Ramsaroop R, Bhoola KD. Immunolocalization of bradykinin receptors on human synovial tissue. Immunopharmacology 1997;36:121-5

Cassim B, Mody G, Bhoola KD. Kallikrein cascade and cytokines in inflamed joints. Pharmacol Ther 2002;94:1-34

Gharavi AG, Lipkowitz MS, Diamond JA, Jhang JS, Phillips RA. Deletion polymorphism of the angiotensin-converting enzyme gene is independently associated with left ventricular mass and geometric remodeling in systemic hypertension. Am J Cardiol 1996;77:1315-9

Ghosh P, Cheras PA. Vascular mechanisms in osteoarthritis. Best Pract Res Clin Rheumatol 2001;15:693-709

Ishigami $\mathrm{T}$, Iwamoto $\mathrm{T}$, Tamura $\mathrm{K}$, Yamaguchi $\mathrm{S}$, Iwasawa $\mathrm{K}$, Uchino $\mathrm{K}$, Umemura S, Ishii $\mathrm{M}$. Angiotensin I converting enzyme (ACE) gene polymorphism and essential hypertension in Japan. Ethnic difference of ACE genotype. Am J Hypertens 1995;8:95-7

Jeng JR, Harn HJ, Jeng CY, Yueh KC, Shieh SM. Angiotensin I converting enzyme gene polymorphism in Chinese patients with hypertension. Am J Hypertens 1997;10:558-61

Kehoe PG, Russ C, Mcllory S, Williams $H$, Holmans $P$, Holmes C, Liolitsa D, Vahidassr D, Powell J, McGleenon B, Liddell M, Plomin R, Dynan K, Williams N, Neal J, Cairns NJ, Wilcook G, Passmore $P$, Lovestone S, Williams J, Owen MJ. Variation in DCP1, encoding ACE, is associated with susceptibility to Alzheimer disease. Nat Genet 1999;21:71-2

Kellgren JK, Lawrence JS. Radiological assessment of osteoarthritis. Ann Rheum Dis 1957;16:494-501

Kennon B, Petrie JR, Small M, Connell JM. Angiotensinconverting enzyme gene and diabetes mellitus. Diabet Med $1999 ; 16: 448-58$

Lee EJ. Population genetics of the angiotensin-converting enzyme gene in Chinese. Br J Clin Pharmacol 1994;37:212-4

Lequesne M, Mry C, Samson M, Gèrard P. Indexes of severity for osteoarthritis of the hip and knee. Validation-value in comparison with other assessment tests. Scand J Rheumatol 1987;65:85-9

Lin JJ, Yueh KC, Chang DC, Lin SZ. Association between genetic polymorphism of angiotensin-converting enzyme gene and Parkinson's disease. J Neurol Sci 2002;199:25-9

Loughlin J, Dowling B, Mustafa Z, Chapman K. Association of the interleukin-1 gene cluster on chromosome $2 q 13$ with knee osteoarthritis. Arthritis Rheum 2002;46:1519-27

MacGregor AJ, Spector TD. Twins and the genetic architecture of osteoarthritis. Rheumatology (Oxford) 1999;38:5838

McKenzie CA, Julier C, Forrester T, McFarlane-Anderson N, 
Keavney B, Lathrop GM, Ratcliffe PJ, Farrall M. Segregation and linkage analysis of serum angiotensin I-converting enzyme levels: evidence for two quantitative-trait loci. Am J Hum Genet 1995;57:1426-35

Min BH, Kim HJ, Lim H, Park CS, Park SR. Effects of ageing and arthritic disease on nitric oxide production by human articular chondrocytes. Exp Mol Med 2001;33:299-302

Nishimura M, Segami N, Kaneyama K, Suzuki T, Miyamaru $M$. Relationships between pain-related mediators and both synovitis and joint pain in patients with internal derangements and osteoarthritis of the temporomandibular joint. Oral Surg Oral Med Oral Pathol Oral Radiol Endod 2002;94:328-32

Papadopoulos KI, Melander O, Orho-Melander M, Groop LC, Carlsson $M$, Hallengren $B$. Angiotensin converting enzyme (ACE) gene polymorphism in sarcoidosis in relation to associated autoimmune diseases. J Intern Med 2000;247:71-7

Park HY, Kwon HM, Kim D, Jang Y, Shim WH, Cho SY, Kim HS. The angiotensin converting enzyme genetic polymorphism in acute coronary syndrome-ACE polymorphism as a risk factor of acute coronary syndrome. J Korean Med Sci 1997:12:391-7

Reginato AM, Olsen BR. The role of structural genes in the pathogenesis of osteoarthritic disorders. Arthritis Res 2002; $4: 337-45$

Rigat B, Hubert C, Alhenc-Gelas F, Cambien F, Corvol P, Soubrier $F$. An insertion/deletion polymorphism in the angio- tensin I-converting enzyme gene accounting for half the variance of serum enzyme levels. J Clin Invest 1990;86: 1343-6

Schachter F, Faure-Delanef L, Guenot F, Rouger H, Froguel $P$, Lesueue-Ginot L, Cohen D. Genetic associations with human longevity at the APOE and ACE loci. Nat Genet 1994; 6:29-32

Seo JC, Han SW, Yin CS, Koh HK, Kim CH, Kim EH, Leem $\mathrm{KH}$, Lee HS, Park HJ, Kim SA, Choe BK, Lee HJ, Yim SV, Kim CJ, Chung JH. Evaluation of a Apo-1/Fas promoter polymorphism in korean stroke patients. Exp Mol Med 2002; $34: 294-8$

Sharma $P$. Meta-analysis of the ACE gene in ischemic stroke. J Neurol Neurosurg Psychiatry 1998;64:227-30

Shin HD. Host genetic epidemiology by single nucleotide polymorphism (SNP) analysis. Exp Mol Med 2001;33:51-69

Vitanen L, Pihlajami J, Halonen $P$, Lehtonen $M$, Kareinen A, Lehto S, Laakso M. Association of angiotensin converting enzyme and plasminogen activator inhibitor-1 promotor gene polymorphisms with features of the insulin resistance syndrome in patients with premature coronary heart disease. Atherosclerosis 2001;157:57-64

Walsh DA, Catravas J, Wharton J. Angiotensin converting enzyme in human synovium: increased stromal [(125)! $] 351 \mathrm{~A}$ binding in rheumatoid arthritis. Ann Rheum Dis 2000;59: 125-31 